\title{
Trabeculated (non-compacted) and compact myocardium in adults: the multi-ethnic study of atherosclerosis
}

\author{
Nadine Kawel ${ }^{1 *}$, Marcelo Nacif ${ }^{1}$, Andrew E Arai ${ }^{3}$, Antoinette S Gomes ${ }^{4}$, William Hundley ${ }^{5}$, Craig Johnson ${ }^{6}$, \\ Martin R Prince ${ }^{7}$, Brandon Stacey ${ }^{5}$, Joao A Lima ${ }^{8}$, David A Bluemke ${ }^{1,2}$
}

From 15th Annual SCMR Scientific Sessions

Orlando, FL, USA. 2-5 February 2012

\section{Background}

A high degree of non-compacted (trabeculated) myocardium in relationship to compact myocardium ( $\mathrm{T} / \mathrm{M}$ ratio $>2.3$ ) has been associated with a diagnosis of left ventricular non-compaction (LVNC). The Multi-Ethnic Study of Atherosclerosis (MESA) is a population-based longitudinal study initiated in July 2000; with 6814 participants (45-84 years, 3601 women) free of recognized cardiovascular disease at enrollment. The purpose of this study was to determine the normal range of the T/ $M$ ratio in MESA and to examine the relationship to demographic and clinical parameters.

\section{Methods}

The thickness of trabeculation and the compact myocardium were measured in eight regions of the left ventricle on long axis cardiac magnetic resonance (CMR) steady-state free precession cine images in 1000 randomly chosen participants of the "MESA 5 " follow-up cohort (551 women; $68.1 \pm 8.9$ years) and $\mathrm{T} / \mathrm{M}$ ratios were calculated.

\section{Results}

In a subset of 323 participants free of cardiac disease and without known LVNC, 140 (43\%) had a T/M ratio $>2.3$ in at least one region (Figure 1) while 20/323 (6.2\%) participants had a $\mathrm{T} / \mathrm{M}$ ratio $>2.3$ in more than two regions (Figure 2). 62/323 (19\%) had a T/M ratio $>2.9$ in one region. Multivariate linear regression model revealed no association of age, height and weight with the maximum $\mathrm{T} / \mathrm{M}$ ratio and trabecluation thickness in

${ }^{1}$ Radiology and Imaging Sciences, National Institutes of Health, Bethesda,

MD, USA

Full list of author information is available at the end of the article participants free of cardiac disease ( $p>0.05)$. Maximum trabeculation thickness was associated with Chinese and African American ethnicities and male gender $(\mathrm{p}<0.05$; $\beta=1.5 \mathrm{~mm}, 1.3 \mathrm{~mm}$ and $1.1 \mathrm{~mm}$, respectively). In participants free of cardiac disease, maximum trabeculation thickness and $\mathrm{T} / \mathrm{M}$ ratio were associated with $\mathrm{LV}$ enddiastolic volume $(p<0.0001 ; \beta=0.03 \mathrm{~mm} / \mathrm{ml}$ and $\beta=0.01 /$ $\mathrm{ml}$, respectively) and end-systolic volume $(\mathrm{p}<0.001$; $\beta=0.06 \mathrm{~mm} / \mathrm{ml}$ and $\beta=0.03 / \mathrm{ml}$, respectively) in adjusted models. Further, there was a negative association of LV ejection fraction with maximum $\mathrm{T} / \mathrm{M}$ ratio $(\mathrm{p}=0.044$; $\beta=-0.02 / \%)$. There was no association of maximum $\mathrm{T} / \mathrm{M}$ ratio with hypertension or myocardial infarction $(p>0.05)$ in adjusted models of the entire cohort $(n=1000)$. Values for $T / M$ ratio depend on measurement technique: At the apical level median $\mathrm{T} / \mathrm{M}$ ratios derived from measurements of short axis images were significantly less than the values obtained on long axis images $(\mathrm{p}=0.017)$.

\section{Conclusions}

Results of the current study suggest a reevaluation of the current CMR criteria for LVNC using a higher cutoff for $\mathrm{T} / \mathrm{M}$ ratio and including the number of affected regions. A uniform definition of measurement technique is necessary.

\section{Funding}

This research was supported by contracts N01-HC95159 through N01-HC-95169 from the National Heart, Lung, and Blood Institute. 

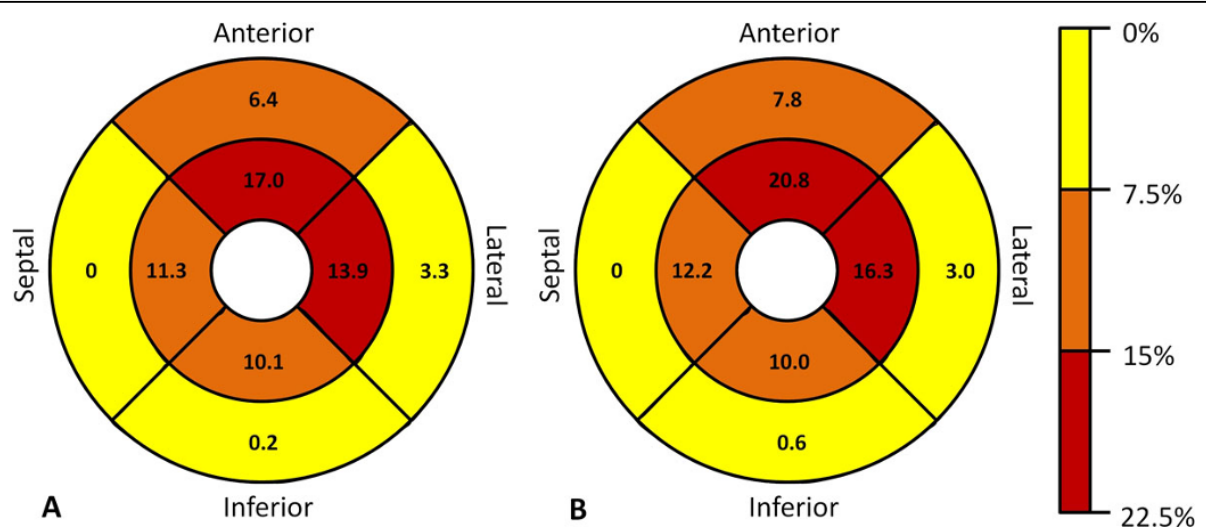

Figure 1 Percent subjects with a T/M ratio $>2.3$ per region at the mid-cavity level (outer circle) and the apical level (inner circle) of the entire cohort (A) and the subset of subjects free of cardiac disease (B).

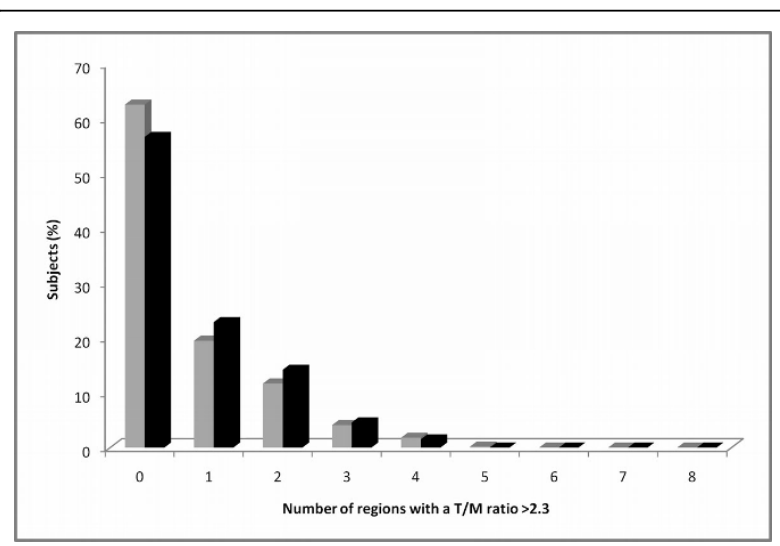

Figure 2 Percent of subjects of the entire cohort (grey bars) and the subset of subjects free of cardiac disease (black bars) with a T/ $M$ ratio $>2.3$ in 0 to 8 regions per subject. T/M ratio $=$ thickness of trabeculation / thickness of compact myocardium.

\section{Author details}

${ }^{1}$ Radiology and Imaging Sciences, National Institutes of Health, Bethesda, MD, USA. ${ }^{2}$ National Institute of Biomedical Imaging and Bioengineering, National Institutes of Health, Bethesda, MD, USA. ${ }^{3}$ National Heart, Lung and Blood Institute, National Institutes of Health, Bethesda, MD, USA.

${ }^{4}$ Department of Radiology, UCLA School for Medicine, Los Angeles, CA, USA. ${ }^{5}$ Department of Internal Medicine / Cardiology, Wake Forest University,

Winston-Salem, NC, USA. ${ }^{6}$ Collaborative Health Studies Coordinating Center, University of Washington, Seattle, WA, USA. ${ }^{7}$ Cornell and Columbia Universities, New York, NY, USA. ${ }^{8}$ Division of Cardiology, Johns Hopkins University, Baltimore, MD, USA.

Published: 1 February 2012

doi:10.1186/1532-429X-14-S1-086

Cite this article as: Kawel et al:: Trabeculated (non-compacted) and compact myocardium in adults: the multi-ethnic study of atherosclerosis. Journal of Cardiovascular Magnetic Resonance 201214 (Suppl 1):086.

\section{Submit your next manuscript to BioMed Central and take full advantage of:}

- Convenient online submission

- Thorough peer review

- No space constraints or color figure charges

- Immediate publication on acceptance

- Inclusion in PubMed, CAS, Scopus and Google Scholar

- Research which is freely available for redistribution

Submit your manuscript at www.biomedcentral.com/submit 